Vietnam Journal of Mechanics, VAST, Vol. 27, No. 1 (2005), pp. 1-12

\title{
BUCKLING ANALYSIS OF LAMINATED CYLINDRICAL COMPOSITE SHELL PANEL UNDER MECHANICAL AND HYGROTHERMAL LOADS
}

\author{
Tran ICh Thinh, Le KIM NGOC \\ Hanoi University of Technology
}

\begin{abstract}
This paper deals with buckling of analysis multilaminated cylindrical shell panels subjected to axial and hygrothermal loadings. The geometrical non-linear analysis is carried out using the Finite Element Method based on a single layer first shear deformation thcory. A nine-nodal isoparametric element with 5 degrees of freedom per node is considered. The effects of different number of layers, lamination angles, length to width ratios and hygrothermal effects are studied.
\end{abstract}

Keywords: Buckling, Composite shell panels, Hygrothermal effects, Finite Element, First-order Shear deformation Theory.

\section{INTRODUCTION}

Composite materials are being increasingly used in aerospace, civil, naval and other high-performance engineering application due to their light weight, high-specific strength and stiffness, excellent thermal characteristics, ease in fabrication and other significant attributes.

The effect of environment on the buckling behaviour of laminated shells and plates was studied by some authors [1], [3], [4].

In [1], Ganesan and all considered the thermal buckling in thin circular cylindrical shells using 3-nodal isoparametric element with 5 d.o.f per node. The buckling of plate and shell with higher-order displacement model, using 8-nodal serendipity element with 10 d.o.f per node are investigated by some authors [2]. Parhi and all [3] examined the hygrothermal effects on dynamic behaviour of multiple laminated composite plate and shell with large displacement model using 8-nodal element with 10 d.o.f per node. Further more, the experimental analysis in [4] showed that the rise of temperature and moisture will reduce the elastic moduli of the materials, induce internal stresses and degrade the strength of the materials. In addition, it was found that if the elastic shear modulus is much smaller than the major in-plane normal modulus, the transverse shear deformation effecting on the stability of the plate and shell will not be negligible even if these structures are not thick [5], [6].

In this paper, the 9-node isoparametric element with 5 d.o.f per node is used with Green- Lagrange strain. The effects of the number of layers, lamination angles, length to width ratios and hygrothermal are studied. In general, for the thin plate and shell panels, a good agreement is found between the obtained results and the results calculated by HSDT (Higher-order Shear Deformation Theory) [2] and by CPT (Classical Plate Theory) [7]. We can see also that hydrothermal environment has considerable effects on the buckling of the cylindrical composite shell panels. 


\section{FUNDAMENTAL FORMULATION}

\subsection{Local and global coordinate systems}

Choose $O X Y Z$ : global coordinate system.

Choose oxyz: local coordinate system.

$R$ is radius of cylindrical shell panel, $L$ is length of straight side, $b$ is circumferential width, $h$ is thickness and the angle $\varphi=b / R$.

Transformation matrix between local and global axes:

$$
\left\{\begin{array}{l}
x \\
y \\
z
\end{array}\right\}=\left[\begin{array}{ccc}
1 & 0 & 0 \\
0 & c & c \\
0 & -s & c
\end{array}\right]\left\{\begin{array}{l}
X \\
Y \\
Z
\end{array}\right\} \text { or }\left\{\begin{array}{l}
X \\
Y \\
Z
\end{array}\right\}=\left[\begin{array}{ccc}
1 & 0 & 0 \\
0 & c & c \\
0 & -s & c
\end{array}\right]\left\{\begin{array}{l}
x \\
y \\
z
\end{array}\right\},
$$

with $s: \sin \varphi, c:=\cos \varphi$

\subsection{The displacement - strain fields}

* The first order displacement field "

$$
\begin{aligned}
& \bar{u}_{(x, y, z)}=u_{(x, y)}^{0}+z \beta_{x(x, y)}, \\
& \bar{v}_{(x, y, z)}=v_{(x, y)}^{0}+z \beta_{y(x, y)}, \\
& \bar{w}_{(x, y, z)}=w_{(x, y)}^{0},
\end{aligned}
$$

where, $u^{0}, v^{0}, w^{0}$ are the mid-surface displacements. $\beta_{x} ; \beta_{y}$ are the components of rotation of the normal to the reference surface in the $X, Z$ and $Y, Z$ - plane, respectively.

* The strain field

The Green-Lagrange strain model is given in the form: $\{\varepsilon\}=\left\{\varepsilon^{l}\right\}+\left\{\varepsilon^{n l}\right\}$, where $\left\{\varepsilon^{l}\right\}$ and $\left\{\varepsilon^{n l}\right\}$ represent the linear and non-linear part, respectively.

The linear part

$$
\left\{\varepsilon^{l}\right\}=\left\{\begin{array}{c}
\varepsilon_{x}^{l} \\
\varepsilon_{y}^{l} \\
\gamma_{x y}^{l} \\
\gamma_{y z}^{l} \\
\gamma_{x z}^{l}
\end{array}\right\}=\left\{\begin{array}{c}
\varepsilon_{x}^{0} \\
\varepsilon_{y}^{0} \\
\gamma_{x y}^{0} \\
\gamma_{y z}^{0} \\
\gamma_{x z}^{0}
\end{array}\right\}+z\left\{\begin{array}{c}
k_{x} \\
k_{y} \\
k_{x y} \\
0 \\
0
\end{array}\right\}=\left\{\begin{array}{c}
u_{, x}^{0} \\
\left(v_{, y}^{0}+\frac{w^{0}}{R}\right) \\
\left(u_{, y}^{0}+v_{, x}^{0}\right) \\
\left(\beta_{y}+w_{, y}^{0}-\frac{v^{0}}{R}\right) \\
\left(\beta_{x}+w_{x}^{0}\right)
\end{array}\right\}+z\left\{\begin{array}{c}
\beta_{x, x} \\
\beta_{y, y} \\
\left(\beta_{x, y}+\beta_{y, x}\right) \\
0 \\
0
\end{array}\right\} .
$$

The non-linear part

$$
\left\{\varepsilon^{n l}\right\}=\left\{\begin{array}{c}
\varepsilon_{x}^{n l} \\
\varepsilon_{y}^{n l} \\
\varepsilon_{x y}^{n l} \\
\varepsilon_{y z}^{n l} \\
\varepsilon_{x z}^{n l}
\end{array}\right\}=\left\{\begin{array}{c}
\frac{1}{2}\left[\bar{u}_{, x}^{2}+\bar{v}_{, x}^{2}+\bar{w}_{, x}^{2}\right] \\
\frac{1}{2}\left[\bar{u}_{, y}^{2}+\left(\bar{v}_{, y}+\frac{\bar{w}}{R}\right)^{2}+\left(\bar{w}_{, y}+\frac{\bar{v}}{R}\right)^{2}\right] \\
{\left[\bar{u}_{, x} \bar{u}_{, y}+\bar{v}_{, x}\left(\bar{v}_{, y}+\frac{\bar{w}}{R}\right)+\bar{w}_{, x}\left(\bar{w}_{, y}-\frac{\bar{v}}{R}\right)\right]} \\
{\left[\bar{u}_{, y} \bar{u}_{, z}+\bar{v}_{, z}\left(\bar{v}_{, y}+\frac{\bar{w}}{R}\right)+\bar{w}_{, z}\left(\bar{w}_{, y}-\frac{\bar{v}}{R}\right)\right]} \\
{\left[\bar{u}_{, x} \bar{u}_{, z}+\bar{v}_{, x} \bar{v}_{, z}+\bar{w}_{, x} \bar{w}_{, z}\right]}
\end{array}\right\}
$$




\subsection{Constitutive equation and hygrothermal effects}

As in classical shell theory, the membrane stress resultants, the bending moment resultants and the shear stress resultants are expressed as follows:

$$
\left\{\begin{array}{l}
\{N\} \\
\{M\} \\
\{Q\}
\end{array}\right\}=\left[\begin{array}{ccc}
{[A]} & {[B]} & {[0]} \\
{[B]} & {[D]} & {[0]} \\
{[0]} & {[0]} & {[F]}
\end{array}\right]\left\{\begin{array}{c}
\left\{\varepsilon^{0}\right\} \\
\{k\} \\
\left\{\gamma^{0}\right\}
\end{array}\right\}
$$

The extensional, bending-stretching and bending stiffnesses of the laminated are the following:

$$
\begin{aligned}
& {\left[A_{i j}, B_{i j}, D_{i j}\right]=\int_{\frac{h}{2}}^{\frac{h}{2}}\left[Q_{i j}^{\prime}\right]\left(1, z, z^{2}\right) d z \text { with }(i, j=1,2,3)} \\
& \text { and } \quad\left[F_{i j}\right]=\int_{\frac{h}{2}}^{\frac{h}{2}} f\left[Q_{i j}^{\prime}\right] d z \quad \text { with } \quad(i, j=4,5) .
\end{aligned}
$$

" $f$ " is the shear correction factor which is derived from the Timoshenko beam concept by applying the energy principle and is assumed as 5/6. It accounts for the non-uniform distribution of transverse shear strain across the thickness of the lamina. " $h$ " is the total thickness of the laminate.

The non-mechanical strains of the $k^{\text {th }}$ lamina due to hygrothermal effects are expressed as:

$$
\left\{\begin{array}{c}
e_{x} \\
e_{y} \\
e_{x y}
\end{array}\right\}=\cdot\left[\begin{array}{ccc}
c^{2} & s^{2} & s c \\
s^{2} & c^{2} & -s c \\
-2 s c & 2 s c & c^{2}-s^{2}
\end{array}\right]\left(\left\{\begin{array}{c}
\alpha_{1} \\
\alpha_{2} \\
0
\end{array}\right\}\left(T-T_{0}\right)+\left\{\begin{array}{c}
\beta_{1} \\
\beta_{2} \\
0
\end{array}\right\}\left(m-m_{0}\right)\right),
$$

where, $c$ is $\cos \theta, s$ is $\sin \theta, \theta_{k}$ is an arbitrary angle of fibers to ox axis; $\alpha_{1}, \alpha_{2}, \beta_{1}, \beta_{2}$ are the thermal coefficients and the moisture coefficients of lamina, respectively; $m_{0}, T_{0}$ are the reference moisture concentration and temperature, respectively; $m, T$ are the elevated moisture concentration and temperature, respectively. In the present analysis, $m_{0}$ and $T_{0}$ are assumed as $0 \%$ and $27^{\circ} \mathrm{C}$, respectively.

The non-mechanical in plane stress and moment resultants are thus given by:

$$
\begin{aligned}
& \left\{N_{x}^{N} N_{y}^{N} N_{x y}^{N}\right\}^{T}=\sum_{k=1}^{n} \int_{h_{k-1}}^{h_{k}}\left[Q_{i j}^{\prime}\right]\{e\}_{k} d z \\
& \left\{M_{x}^{N} M_{y}^{N} M_{x y}^{N}\right\}^{T}=\sum_{k=1}^{n} \int_{h_{k-1}}^{h_{k}}\left[Q_{i j}^{\prime}\right]\{e\}_{k} z d z \quad \text { with } \quad(i, j=1,2,6)
\end{aligned}
$$




\section{FINITE ELEMENT PROCEDURE}

In numerical analysis by the F.E.M, the element model we choose is a nine-nodal isoparametric element with 5 d.o.f considered at each node of the element that are $u, v, w, \beta_{x}$ and $\beta_{y}$. Where, $\beta_{x}$ and $\beta_{y}$ are the components of rotation of the normal to the reference surface in the $X, Z$ and $Y, Z$ - plane, respectively. The displacement field and geometrical parameters are thus given as:

$$
\begin{aligned}
& u=\sum_{i=1}^{9} N_{i} u_{i} ; \quad v=\sum_{i=1}^{9} N_{i} u_{i} ; \quad w=\sum_{i=1}^{9} N_{i} w_{i} ; \\
& \beta_{x}=\sum_{i=1}^{9} N_{i} \beta_{x i} ; \quad \beta_{y}=\sum_{i=1}^{9} N \beta_{y i} ; \\
& x=\sum_{i=1}^{9} N_{i} x_{i} ; \quad y=\sum_{i=1}^{9} N_{i} y_{i} ;
\end{aligned}
$$

The interpolation functions $N_{i}$ are given as [10]:

$$
\begin{array}{lll}
N_{1}=\frac{1}{4}(1-\xi)(1-\eta) \xi \eta ; & N_{4}=\frac{1}{2}(1+\xi)\left(1-\eta^{2}\right) \xi ; & N_{7}=-\frac{1}{4}(1-\xi)(1+\eta) \xi \eta \\
N_{2}=-\frac{1}{2}\left(1-\xi^{2}\right)(1-\eta) \eta ; & N_{5}=\frac{1}{4}(1+\xi)(1+\eta) \xi \eta ; & N_{8}=-\frac{1}{2}(1-\xi)\left(1-\eta^{2}\right) \xi \\
N_{3}=-\frac{1}{4}(1+\xi)(1-\eta) \xi \eta ; & N_{6}=\frac{1}{2}\left(1-\xi^{2}\right)(1+\eta) \eta ; & N_{9}=\left(1-\xi^{2}\right)\left(1-\eta^{2}\right)
\end{array}
$$

The stiffness matrix of element is given by:

$$
\left[K_{e}\right]=\int_{-1}^{1} \int_{-1}^{1}\left[\begin{array}{c}
{\left[N_{i}\right]^{T}\left[L_{1}\right]^{T}[A]\left[L_{1}\right]\left[N_{i}\right]+\left[N_{i}\right]^{T}\left[L_{1}\right]^{T}[B]\left[L_{2}\right]\left[N_{i}\right]} \\
+\left[N_{i}\right]^{T}\left[L_{2}\right]^{T}[B]\left[L_{1}\right]\left[N_{i}\right]+\left[N_{i}\right]^{T}\left[L_{2}\right]^{T}[D]\left[L_{2}\right]\left[N_{i}\right] \\
+\left[N_{i}\right]^{T}\left[L_{3}\right]^{T}[F]\left[L_{3}\right]\left[N_{i}\right]
\end{array}\right]|J| d \xi d \eta
$$

where, $\mathbf{J}$ is the Jacobian matrix; $\left[L_{i}\right]$ are usual strain-displacement operator matrix.

Putting (2.1) into (2.3), the non-linear strains are modified. And then, the $\left\{\varepsilon^{n l}\right\}$ are expressed in matrix form as $\left\{\varepsilon^{n l}\right\}=\left\{\varepsilon_{x}^{n l} \varepsilon_{y}^{n l} \varepsilon_{x y}^{n l} \varepsilon_{x z}^{n l} \varepsilon_{y z}^{n l}\right\}^{T}=\frac{1}{2}[\Omega]_{5 \times 9}\left\{\delta_{e}\right\}_{9 \times 1}$, where, [ $[\Omega]$ is the multiplier matrix (appendix) and:

$$
\begin{aligned}
\left\{\delta_{\mathbf{e}}\right\}=\{ & \left(u_{, x}^{0}+z \beta_{x, x}\right),\left(v_{, x}^{0}+z \beta_{y, x}\right), w_{, x}^{0},\left(u_{, y}^{0}+z \beta_{x, y}\right),\left(\left(v_{, y}^{0}+\frac{w^{0}}{R}\right)+z \beta_{y, y}\right), \\
& \left.\left(w_{, y}^{0}+\left(-\frac{v^{0}}{R}\right)\right), \beta_{x}, \beta_{y}, 0\right\}^{T} .
\end{aligned}
$$

This vector can be expressed in the form of nodal degree of freedom: $\left\{\delta_{e}\right\}_{9 \times 1}=$ $[G]_{9 \times 45}\left\{q_{e}\right\}_{45 \times 1}$, where, $\left\{q_{e}\right\}=\left\{u_{1} v_{1} w_{1} \beta_{x 1} \beta_{y 1} \ldots \beta_{x 9} \beta_{y 9}\right\}_{45 \times 1}^{T}$ is the element displacement vector, $[G]$ is the initial strain-displacement operator matrix. 
The strain energy is determined by initial stresses in the form [3] as well as [8]:

$$
\left[U_{e}^{\sigma, N}\right]=\frac{1}{2} \int_{V_{e}}\left\{\delta_{e}\right\}^{T}\left[\begin{array}{ccc}
S_{e} & 0 & 0 \\
0 & S_{e} & 0 \\
0 & 0 & S_{e}
\end{array}\right]\left\{\delta_{e}\right\} d V
$$

where,

$$
\left[S_{e}\right]_{3 \times 3}=\left[\begin{array}{ccc}
\sigma_{x}^{i} & \tau_{x y}^{i} & \tau_{x z}^{i} \\
& \sigma_{y}^{i} & \tau_{y z}^{i} \\
(S y m) & & 0
\end{array}\right]
$$

superscript $\left({ }^{i}\right)$ represents corresponding initial stresses.

So, the initial stress (or geometric) stiffness matrices of element are expressed by:

$$
K_{e}^{\sigma, N}=\int_{V_{e}}[G]^{T}\left[\begin{array}{ccc}
S_{e} & 0 & 0 \\
0 & S_{e} & 0 \\
0 & 0 & S_{e}
\end{array}\right][G] d V .
$$

After some calculations, we obtain:

$$
\left[K_{e}^{\sigma, N}\right]=\left[K_{e 1}^{\sigma, N}\right]+\left[K_{e 2}^{\sigma, N}\right]+\left[K_{e 3}^{\sigma, N}\right]+\left[K_{e 4}^{\sigma, N}\right],
$$

where,

$$
\begin{aligned}
{\left[K_{e 1}^{\sigma, N}\right]=} & \int_{-1}^{1} \int_{-1}^{1}\left[N_{i}\right]^{T}\left[L_{1}^{\sigma}\right]^{T}\left[\begin{array}{ccc}
S_{e 1} & 0 & 0 \\
0 & S_{e 1} & 0 \\
0 & 0 & S_{e 1}
\end{array}\right]\left[L_{1}^{\sigma}\right]\left[N_{i}\right]|J| d \xi d \eta, \\
{\left[K_{e 2}^{\sigma, N}\right]=} & \int_{-1}^{1} \int_{-1}^{1}\left[N_{i}\right]^{T}\left[L_{2}^{\sigma}\right]^{T}\left[\begin{array}{ccc}
S_{e 2} & 0 & 0 \\
0 & S_{e 2} & 0 \\
0 & 0 & S_{e 2}
\end{array}\right]\left[L_{1}^{\sigma}\right]\left[N_{i}\right]|J| d \xi d \eta \\
{\left[K_{e 3}^{\sigma, N}\right]=} & \int_{-1}^{1} \int_{-1}^{1}\left[N_{i}\right]^{T}\left[L_{1}^{\sigma}\right]^{T}\left[\begin{array}{ccc}
S_{e 3} & 0 & 0 \\
0 & S_{e 3} & 0 \\
0 & 0 & S_{e 3}
\end{array}\right]\left[L_{2}^{\sigma}\right]\left[N_{i}\right]|J| d \xi d \eta \\
{\left[K_{e 4}^{\sigma, N}\right]=} & \int_{-1}^{1} \int_{-1}^{1}\left[N_{i}\right]^{T}\left[L_{2}^{\sigma}\right]^{T}\left[\begin{array}{ccc}
S_{e 4} & 0 & 0 \\
0 & S_{e 4} & 0 \\
0 & 0 & S_{e 4}
\end{array}\right]\left[L_{2}^{\sigma}\right]\left[N_{i}\right]|J| d \xi d \eta,
\end{aligned}
$$


with

$$
\begin{aligned}
& {\left[S_{e 1}\right]_{3 \times 3}=\left[\begin{array}{ccc}
N_{x} & N_{x y} & Q_{x} \\
& N_{y} & Q_{y} \\
(S y m) & & 0
\end{array}\right],} \\
& {\left[S_{e 2}\right]_{3 \times 3}=\left[S_{e 3}\right]_{3 \times 3}=\left[\begin{array}{ccc}
M_{x} & M_{x y} & Q_{x}^{*} \\
& M_{y} & Q_{y}^{*} \\
(S y m) & & 0
\end{array}\right],} \\
& {\left[S_{e 4}\right]_{3 \times 3}=\left[\begin{array}{ccc}
M_{x}^{*} & M_{x y}^{*} & Q_{x}^{* *} \\
(S y m) & M_{y}^{*} y & Q_{y}^{* *} \\
(S y m & & 0
\end{array}\right],}
\end{aligned}
$$

in which, superscript $\left({ }^{*}\right)$ and $\left({ }^{* *}\right)$ represent corresponding the higher-order force resultants.

The transformation matrix, $[T]$, from local to global axes is in the form:

$$
[T]_{9 \times 9}=\left[\begin{array}{cccc}
{\left[t_{i}\right]} & 0 & K & 0 \\
& {\left[t_{i}\right]} & & \\
& & 0 & M \\
(\text { Sym }) & & & {\left[t_{i}\right]}
\end{array}\right] \text { with }\left[t_{i}\right]=\left[\begin{array}{ccccc}
1 & 0 & 0 & 0 & 0 \\
0 & c & -s & 0 & 0 \\
0 & s & c & 0 & 0 \\
0 & 0 & 0 & 1 & 0 \\
0 & 0 & 0 & 0 & c
\end{array}\right]_{(5 \times 5)}
$$

Finally, the buckling problem is reduced to the eigenvalue problem:

$$
\left([\mathbf{K}]+\left[\mathbf{K}^{\mathbf{N}}\right]-\lambda\left[\mathbf{K}^{\sigma}\right]\{\mathbf{Q}\}=\mathbf{0} .\right.
$$

In order to solve this eigenvalue problem, the Subspace Iteration Method is applied [14]. The least eigenvalue $\lambda$ corresponds to the buckling load of the shell panel will be obtained.

Note that the mechanical load is an uniform-axial compressive load on curved edges. The $(3 \times 3)$ Gauss quadrature is used to calculate the integral expressions.

The element nodal load vector due to hygrothermal effects is determined by

$$
\left[\mathbf{P}_{\mathbf{e}}^{\mathbf{N}}\right]=\int_{S_{e}}[\mathbf{B}]^{T}\left\{\mathbf{F}^{N}\right\} d s,
$$

where, $\left\{\mathbf{F}^{\mathbf{N}}\right\}=\left\{N_{x}^{N} N_{y}^{N} N_{x y}^{N} M_{x}^{N} M_{y}^{N} M_{x y}^{N} 00\right\}$ as mentioned earlier in (2.7) and $[B]=$ $[L]\left[N_{i}\right]$ is the strain-displacement matrix.

The solution procedure for the buckling problem includes the following steps:

- From (3.1), one can compute the stiffness matrix $[K]$ by assembling the element stiffness matrices. 
- Solution of the prebuckling problem to determined the stress resultants due to the mechanical load:

$$
[\mathbf{K}]\{\mathbf{Q}\}=\{\mathbf{P}\}
$$

where, $\{\mathbf{Q}\}$ is the global displacement vector.

- Compution of the prebuckling geometric stiffness matrix, $\left[\mathbf{K}^{\sigma}\right]$.

- Solution of the hygrothermal problem to obtain the stress resultants due to the temperature change and moisture concentration:

$$
[\mathbf{K}]\{\mathbf{Q}\}=\left\{\mathbf{P}^{\mathbf{N}}\right\} \text {. }
$$

- Computation of the initial stress (or geometric) stiffness matrix, $\left[\mathbf{K}^{\mathbf{N}}\right]$.

- Determination of the buckling load from (3.6).

\section{NUMERICAL RESULTS AND DISCUSSION}

In order to bring out numerical solutions of the buckling problem with and without hygrothermal effects for a cylindrical composite shell panel, in this section, some kinds of composite shell panels were calculated by the Matlab software (a mesh of $4 \times 4$ elements for a full shell panel).

Geometrical parameters are as in Fig. 1.

- Length of straight side: $L$

- Circumferential width: $b$

- Thickness: $h$

- Radius of cylindrical shell panel: $R$

$-\varphi=\frac{b}{R}$


Fig. 1. Geometrical parameter

\subsection{The buckling parameter of cylindrical panels subjected to axial compression}

A symmetric lay-up $\left[0 /-\theta^{0} / \theta^{0} / 90^{0}\right]_{s}, \theta$ : fibre angle ranging from $0^{0}-90^{0}$ with steps of $15^{0}$ is analyzed.

The material and geometrical properties are: $E_{1}=181 \mathrm{GPa} ; E_{2}=10.3 \mathrm{GPa} ; G_{12}=$ $G_{13}=G_{23}=7.17 \mathrm{GPa} ; \nu_{12}=\nu_{13}=\nu_{23}=0.28 ; h=1 \mathrm{~mm} ; R / h=150 ; L / R=1$ and $b / L$ $=1.309,1.047$ and 0.786 . 
Boundary conditions are imposed as in Table 1 (note: 0 - free to move, 1 - fixed).

The uniaxial non-dimensionalized buckling parameter $\lambda=F_{c r} R / E_{1} h^{2}$ versus lamination angle fibre $\theta^{0}$ for a thin cylindrical panel $(R / h=150)$ is presented in Table 2 and Fig. 2 - 4 .

Table 1. Boundary conditions

\begin{tabular}{|l|c|c|c|c|c|}
\hline & $u$ & $v$ & $w$ & $\beta_{x}$ & $\beta_{y}$ \\
\hline Top & 0 & 1 & 1 & 1 & 0 \\
\hline Right side & 0 & 1 & 1 & 1 & 1 \\
\hline Bottom & 0 & 1 & 1 & 1 & 0 \\
\hline Left side & 1 & 1 & 1 & 1 & 1 \\
\hline
\end{tabular}

Table 2. Effects of angle fibre on buckling load parameter $\lambda(R / h=150)$

\begin{tabular}{|c|c|c|c|c|c|c|c|c|c|}
\hline \multirow{3}{*}{$\theta^{0}$} & \multicolumn{9}{|c|}{$\lambda==F_{c r} \bar{R} / E_{1} h_{2}$} \\
\hline & \multicolumn{3}{|c|}{$\bar{b} / L=1.309$} & \multicolumn{3}{|c|}{$b / L=1.047$} & \multicolumn{3}{|c|}{$\bar{b} / \bar{L}=0.786$} \\
\hline & $\overline{\mathrm{CPT}}[7]$ & HSDT[2] & Present & CPT[7] & HSDT [2] & Present & СरT[7] & HSDT $[2]$ & Present \\
\hline 0 & 0.117 & 0.121 & 0.118 & 0.123 & 0.122 & 0.119 & 0.126 & 0.129 & 0.129 \\
\hline 15 & 0.170 & 0.147 & 0.149 & 0.147 & 0.147 & 0.151 & 0.155 & 0.159 & 0.156 \\
\hline 30 & 0.197 & 0.190 & 0.187 & 0.194 & 0.192 & 0.188 & 0.202 & 0.205 & 0.202 \\
\hline 45 & 0.221 & 0.211 & $\overline{0.215}$ & 0.222 & 0.220 & 00.217 & 0.230 & $\overline{0.232}$ & 0.233 \\
\hline 60 & 0.212 & 0.206 & $0 . \overline{208}$ & 0.214 & 0.214 & 0.212 & 0.225 & 0.230 & 0.227 \\
\hline 75 & 0.171 & 0.174 & 0.175 & 0.174 & 0.179 & 0.177 & 0.187 & 0.193 & 0.192 \\
\hline 90 & 0.142 & 0.147 & 0.151 & 0.144 & 0.155 & 0.155 & 0.155 & 0.163 & 0.160 \\
\hline
\end{tabular}

From the Table 2 and Fig. 2 - 4, we see that a good agreement is found between the present results, the numerical predictions of the HSDT and the numerical predictions of the CPT. Fibre angle influences considerably on the stability of the cylindrical shell panel. The $\left[0 /-45^{\circ} / 45^{\circ} / 90^{\circ}\right]_{s}$ is the most stable; the $\left[0^{\circ} / 0^{\circ} / 0^{\circ} / 90^{\circ}\right]_{s}$ is the least stable. The difference of $\lambda$ (between the $\left[0 /-45^{\circ} / 45^{\circ} / 90^{\circ}\right]_{s}$ and the $\left[0^{\circ} / 0^{\circ} / 0^{\circ} / 90^{\circ}\right]_{s}$ shell panel) is about $45 \%$ when $b / L=1.309$, about $44 \%$ when $b / L=1.047$ and about $45 \%$ when $b / L=$ 0.786 .



Fig. 2. Effects of angle fibre on buckling load parameter $\lambda$ with $b / L=1.309 ; R / h=150$
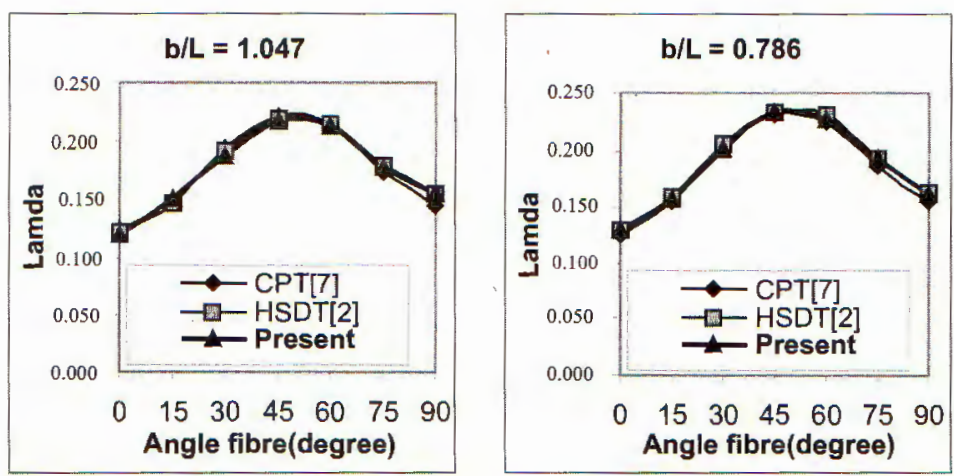

Fig. 3. Effects of angle fibre on buckling load parameter $\lambda$ with $b / L=1.047 ; R / h=150$
Fig. 4. Effects of angle fibre on buckling load parameter $\lambda$ with $b / L=0.786 ; R / h=150$ 
The uniaxial non-dimensionalized buckling parameter $\lambda=F_{c r} R / E_{1} h^{2}$ versus lamination angle fibre $\theta^{0}$ for a thick cylindrical panel $(R / h=15)$ is presented in Fig. $5-7$.

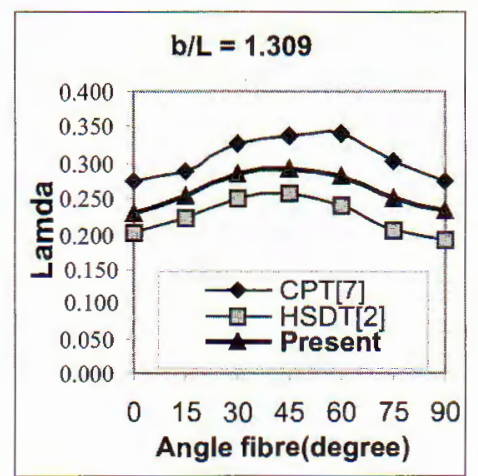

Fig. 5. Effects of angle fibre on buckling load parameter with $b / L=1.309 ; R / h=15$

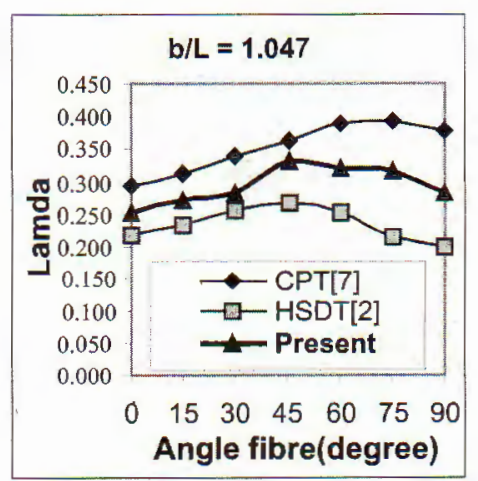

Fig.6. Effects of angle fibre on buckling load parameter with $b / L=1.047 ; R / h=15$

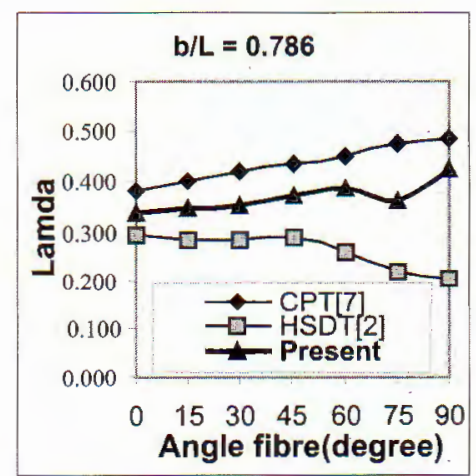

Fig. 7. Effects of angle fibre on buckling load parameter with $b / L=0.786 ; R / h=15$

From the Fig. 5 - 7, we see that the difference of the numerical results between Present and CPT models ranges from about $10 \%$ to $31 \%$; between Present and HSDT models ranges from about $11 \%$

\subsection{Buckling load parameter of composite plates $(R=\infty)$ subjected to axial compression}

The antisymmetric lay-up $\left[\theta^{0} /-\theta^{0} / \ldots\right]_{-s}, \theta^{0}$ : fibre angle ranging from $0^{0}-90^{0}$ with steps of $15^{0}$ is analyzed.

The material and geometrical properties are: $E_{2}=6.9 \mathrm{GPa} ; E_{1} / E_{2}=40 \mathrm{GPa} ; G_{12}=$ $G_{13}=G_{23}=3.45 \mathrm{GPa} ; \nu_{12}=\nu_{13}=\nu_{23}=0.25 ; h=5 \mathrm{~mm} ; L / h=100 ; L / a=1$.

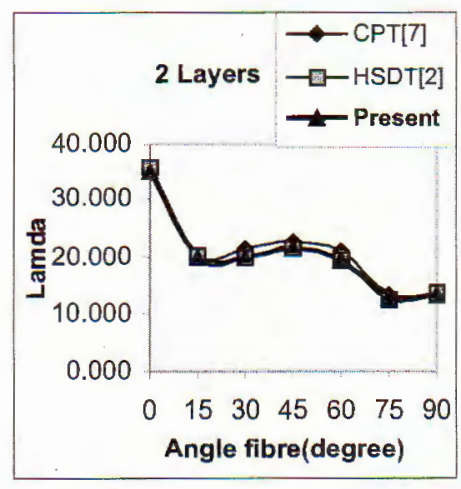

Fig. 8. Effect of number of layers and angle fibre on buckling load parameter $\lambda, 2$ layers

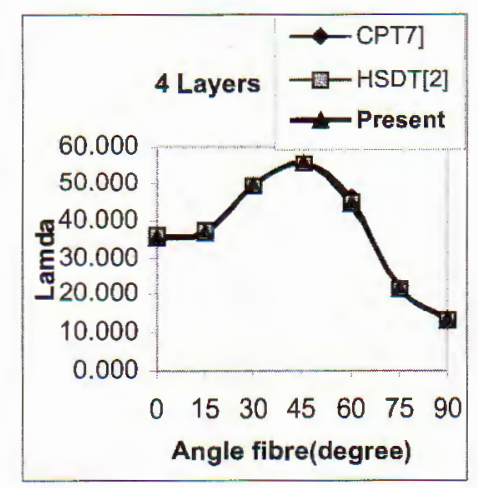

Fig. 9. Effect of number of layers and angle fibre on buckling load parameter $\lambda, 4$ layers

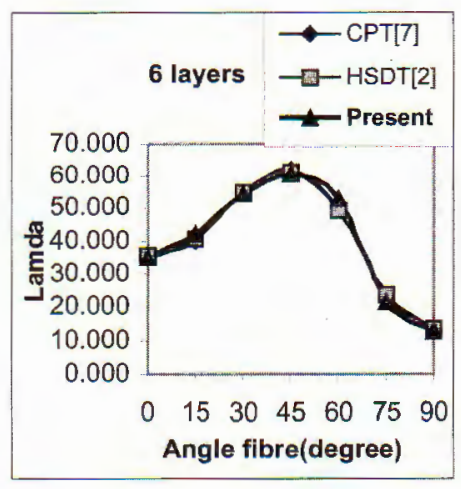

Fig. 10. Effect of number of layers and angle fibre on buckling load parameter $\lambda, 6$ layers 
Boundary conditions are imposed as in table 3. The effect of number of layer on the non-dimensional buckling parameter $\lambda=F_{c r} a^{2} / E_{2} h^{3}$ for an antisymmetric thin laminated square plate $(a / h=100)$ are presented in Fig. 8 - 10 .

From the Fig. 8 - 10 we see that a good agreement is observed for thin plate between the proposed model and the alternative solutions. It is possible to say that the mathematical model is reasonable.

Table 3. Boundary conditions

\begin{tabular}{|l|c|c|c|c|c|}
\hline & $u$ & $v$ & $w$ & $\beta_{x}$ & $\beta_{y}$ \\
\hline Top & 0 & 0 & 1 & 1 & 0 \\
\hline Right side & 0 & 0 & 1 & 0 & 1 \\
\hline Bottom & 0 & 1 & 1 & 1 & 0 \\
\hline Left side & 1 & 0 & 1 & 0 & 1 \\
\hline
\end{tabular}

\subsection{Hygrothermal effects on the buckling of laminated cylindrical composite shell panel}

Assume that the change of temperature is constant in each layer. $T_{0}: 27^{0} \mathrm{C} ; T: 27^{0} \mathrm{C}$ and $152^{\circ} \mathrm{C}$ thus, $\Delta T: 0^{\circ} \mathrm{C}$ and $125^{\circ} \mathrm{C}$ and the change of moisture concentration is constant from the external layer to internal one with $\Delta m_{s}=1.5 \%$. (the shell panel was almost saturated).

The symmetric lay-up $\left[0 /-\theta^{0} / \theta^{0} / 90^{0}\right]_{s}, \theta^{0}$ : fibre angle ranging from $0^{0}-90^{0}$ with steps of $15^{\circ}$ is analyzed. The material and geometrical properties are: $E_{1}=181 \mathrm{GPa}$; $E_{2}=10.3 \mathrm{GPa} ; G_{12}=G_{13}=G_{23}=7.17 \mathrm{GPa} ; \nu_{12}=\nu_{13}=\nu_{23}=0.28 ; h=1 \mathrm{~mm} ; R / h=$ $150 ; L / R=1$ and $b / L=1.309,1.047$ and 0.786 . Boundary conditions are as in Table 1 .

The non-dimensionalized buckling load parameters $\lambda=\left(F_{c r}^{N} \cdot R / E_{1} \cdot h^{2}\right)$ when the thin shell panel subjected to temperature and moisture simultaneously are as in the Table 4 and Fig. 11-13. (superscript $\left({ }^{N}\right)$ represents corresponding non-mechanical load).

Table 4. Hygrothermal effects and angle fibre on buckling load parameter $\lambda$

\begin{tabular}{|c|c|c|c|c|c|c|c|c|c|}
\hline \multirow{4}{*}{$\theta^{0}$} & \multicolumn{9}{|c|}{$\lambda=F_{c r} R / E_{1} h^{2}$} \\
\hline & \multicolumn{3}{|c|}{$b / L=1.309$} & \multicolumn{3}{|c|}{$b / L=1.047$} & \multicolumn{3}{|c|}{$b / L=0.786$} \\
\hline & \multicolumn{2}{|c|}{ Present } & \multirow[t]{2}{*}{ (III) } & \multicolumn{2}{|c|}{ Present } & \multirow[t]{2}{*}{ (III) } & \multicolumn{2}{|c|}{ Present } & \multirow[t]{2}{*}{ (III) } \\
\hline & (I) & (II) & & (I) & (II) & & (I) & (II). & \\
\hline 0 & 0.120 & 0.098 & $18.1 \%$ & 0.119 & 0.098 & $17.5 \%$ & 0.129 & 0.108 & $16.3 \%$ \\
\hline 15 & 0.154 & 0.119 & $22.6 \%$ & 0.151 & 0.118 & $21.7 \%$ & 0.156 & 0.124 & $20.7 \%$ \\
\hline 30 & 0.192 & 0.139 & $27.7 \%$ & 0.187 & 0.137 & $26.5 \%$ & 0.202 & 00.150 & $25.5 \%$ \\
\hline 45 & 0.215 & 0.150 & $30 . \overline{2 \%}$ & 0.217 & 0.153 & $29.4 \%$ & 0.233 & 0.167 & $28.4 \%$ \\
\hline 60 & 0.208 & 0.146 & $29.9 \%$ & 0.212 & 0.151 & $28.9 \%$ & 0.227 & 0.164 & $27.9 \%$ \\
\hline 75 & 0.175 & 0.133 & $24.2 \%$ & 0.177 & 0.135 & $23.9 \%$ & 0.192 & 0.148 & $22.9 \%$ \\
\hline 90 & 0.151 & 0.132 & $12.4 \%$ & 0.155 & 0.136 & $11.9 \%$ & 0.160 & 0.143 & $10.9 \%$ \\
\hline
\end{tabular}

(I) without hygrothermal;(II) with hygrothermal; (III) Discrepancy.

From the Tables 4 and Fig. 11 - 13, we see that the environment has considerable effects on the buckling load parameter $(\lambda)$ of the cylindrical composite shell panel. The reductions 
of the $\lambda$ for the $\left[0 /-\theta^{0} / \theta^{0} / 90^{0}\right]_{s}$ shell panel range from about $10 \%$ to $30 \%$. When subjected to the hygrothermal effects, the $\lambda$ for the $\left[0 / 90^{0} / 90^{\circ} / 90^{0}\right]_{s}$ shell panel is least degraded (about $10 \%$ ); the $\lambda$ for the $\left[0 /-45^{0} / 45^{0} / 90^{0}\right]_{s}$ shell panel is most degraded (about $30 \%$ ), although this configuration is the most stable in the case of without hygrothermal load.

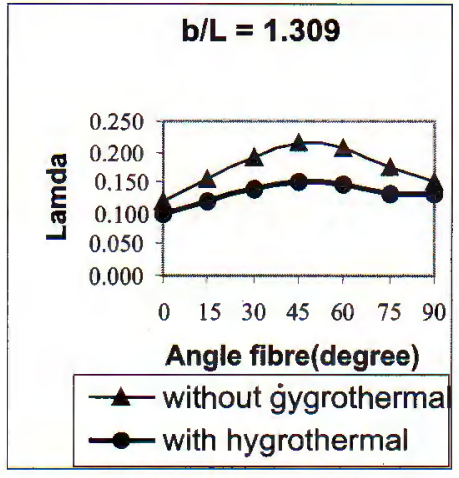

Fig. 11. Hygrothermal effects and angle fibre on buckling load parameter with $b / L=1.309$
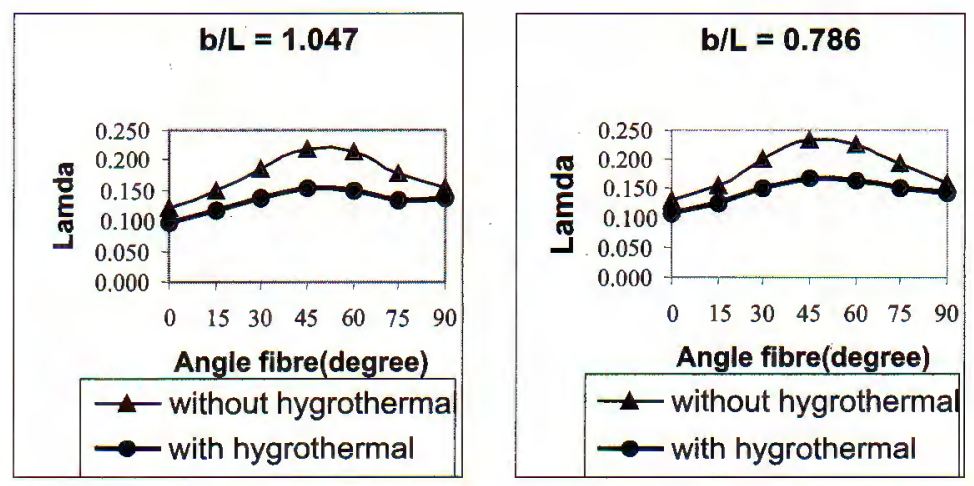

Fig. 12. Hygrothermal effects and angle fibre on buckling load parameter $\lambda$ with $b / L=1.047$
Fig. 13. Hygrothermal effects and angle fibre on buckling load parameter with $b / L=0.786$

\section{CONCLUSION}

The single layer first shear deformation with Green-Lagrange strain model was applied in modeling the buckling behaviour of composite shell panels. In the Finite Element Procedure, the 9-nodal isoparametric element with 5 degrees of freedom per node was chosen. The following broad conclusions may be made from the results presented in the earlier section:

1. For the thin plate and shell panels, the present results obtained by using a full panel $4 \times 4$ finite element mesh are good argreement with existing solutions (CPT and HSDT). The present model gives, relatively speaking, faster convergent solution when compared to the HSDT model $(10 \times 10 \mathrm{mesh})$.

2. For the thick plate and shell panels, CPT overpredicts the buckling loads; HSDT underpredicts the buckling loads and the present model gives the intermediate values of buckling loads when the number of layer is increased. It can be noted that the transverse shear deformation has effect on the buckling loads of the composite shell panels.

3. Concerning the hygrothermal effects, one can see the considerable influence on the buckling parameters of the shell panels. For example, the buckling parameter for the $\left[0 /-45^{0} / 45^{0} / 90^{0}\right]_{s}$ is degraded until $30 \%$ (when $\Delta m_{s}=1.5 \%$ and $\Delta T=125^{0} \mathrm{C}$ ).

From all obtained results, it is necessary to pay attention to the effects of the number of layers, lamination angles, length to width ratios, especially, effects of temperature and moisture in design as well as in studying the static or dynamic behaviour of laminated composite shells.

This publication is completed with financial support from the National Basic Research Program in Natural Science. 


\section{REFERENCES}

1. N. Ganesan, Ravikiran Kadoli, Buckling and dynamic analysis of thermopiezoelectric composite cylindrical shell, Composite and Structures 59 (2003) 45-60.

2. Jos Simes Moita, Cristvo M. Mota Soares, Carlos A.Mota Soares, Buckling and dynamic behavior of laminated composite structures using a discrete higher-order displacement model, Computers and Structures 73 (1999) 407-423.

3. P. K. Parhi, S. K. Bhattacharyya, P. K. Sinha, Hygrothermal effects on the dynamic behavior of multi laminated composite plates and shells, Journal of Sound and Vibration 248 (2) (2001) 195-214.

4. C. H. Shen and G. S. Springer, Moisture absorption and desorption of composite material, J. comp. Mater. 10 (1976) 2-20.

5. G. A. Cohen, Effect of transverse shear deformation on anisotropic plate buckling, J. comp. Mater. 16 (1982) 301-312.

6. N. D. Phan and J. N. Reddy, Analysis of laminated composite plates using a high-order shear deformation theory, Int. J. Numer. Math. Engine 21 2201-2219.

7. J. S. Moita, C. M. Mota Soares ,C. A. Mota Soares ., Vibration and buckling of thin laminated composite structures, Education, Practice and Promotion of Computational Methods in Engineering Using Small Computers, 2 (1995) 263-1269, Korea. Korea Techno.

8. O. C. Zienkievicz, The Finite Element Method in Engineering Science, Maidenhead, Mc.GrawHill Publishing Co.Ltd, 1975.

9. Trần Ích Thịnh, Vật Liệu Composite - Co Học và Tính Toán Kết Cấu, Nxb Giáo dục, Hà Nội, 1994 .

10. Chu Quốc Thắng, Phưong pháp phần tủ hũu hạn, Nxb Khoa học và k̃̃ thuật, 1997.

11. S. Ahmad, B. M. Irons and O. C. Zienkiewicz, Analysis of thick and thin shell structures by curved element, Int. J. Numer. Math. Engine 2 (1970) 419-453.

12. H. Parisch,A critical survey of the 9-node degenerated shell element with special emphasis on thin shell application and reduced integration, Comp. Math. appl. Mech. Engine 20 (1979) 323-350.

13. K. Stolarski and T. Belytschko, Shear and membrane locking in curved Co element, Comp. Math. appl. Mech. Engine 41 (1983) 279-296.

14. Klaus-Jurgen Bathe, Finite Element Procedures, pp.954-965.

Received November 15, 2004

Revised December 10, 2004

\section{PHÂN TÍCH ỔN DỊNH MẢNH VỎ TRỤ COMPOSITE LỚP DƯớI TÁC DỤNG CỪA TẢI TRộnG CƠ HọC VÀ NHIẸT- ẨM}

Báo cáo tập trung nghiên cứu ổn định đàn hồi mảnh vỏ trụ composite lớp chịu tác dụng của lực nén dọc trục trong môi trường nhiệt-ăm. Phân tích được thực hiện nhờ Phần từ hữu hạn tứ giác 9 nút dựa vào lý thuyết biến dạng bậc nhất, có tính đến yếu tố phi tuyến hình học. Ảnh hươnng của số lớp vật liệu, góc đặt cốt, tỉ số chiều dài/chiều rộng và của yếu tố nhiệt- ã̉m đã được kháo sát. 